\title{
EducaTrans: um Jogo Educativo para o Aprendizado do Trânsito
}

\author{
Gilda Aparecida de Assis ${ }^{1,2}$, Irene K. Ficheman ${ }^{1}$, Ana Grasielle Dionísio Corrêa ${ }^{1}$, \\ Márcio Lobo Netto ${ }^{1}$, Roseli de Deus Lopes ${ }^{1}$ \\ ${ }^{1}$ Laboratório de Sistemas Integráveis (LSI) - Escola Politécnica da \\ Universidade de São Paulo (USP) \\ Avenida Prof. Luciano Gualberto, travessa 3, nº 158 - 05508-970 - São Paulo -Brasil \\ ${ }^{2}$ Centro Universitário FEEVALE \\ RS239, nº 2755, Vila Nova - 93352000 - Novo Hamburgo - RS - Brasil \\ \{gildaaa, irene, anagrasi, lobonett, roseli\} @lsi.usp.br
}

Resumo. Este artigo apresenta o jogo EducaTrans, um jogo educacional que tem por objetivo a Educação no Trânsito, um tema transversal de ensino na Educação Básica. Para suportar o jogo aqui apresentado foi criada uma proposta de game engine educacional. O EducaTrans utiliza algoritmos genéticos como mecanismo de evolução dos pedestres autônomos e oferece uma ferramenta divertida e desafiadora onde o aprendiz poderá navegar em um ambiente que reproduz um cenário real com regras de trânsito bem definidas.

Palavras-chave: Jogos educacionais, Game engine, Educação no trânsito.

\begin{abstract}
This paper presents the digital game EducaTrans, an educational game that has for objective the Education in the Transit, a transversal subject of education in the Basic Education. To support this game, a game engine to develop educational digital games was created. The EducaTrans uses genetic algorithms as an evolution mechanism for the autonomous agents, which are the pedestrians. It offers a fun and challenging tool where the learner will be able to navigate in an environment that reproduces a real scenery with clearly defined rules of transit.
\end{abstract}

Keys-words: Educational games, Game engine, Transit education. 


\section{Introdução}

Vários autores afirmam que a motivação é um dos principais problemas que afetam o processo de ensino-aprendizagem. Jesús Alonso Tapia e Enrique Caturla Fita (1999), afirmam que "os alunos não tem interesse em aprender, pois falta motivação". Desta forma, a construção de jogos educacionais vem contribuir, para a resolução de um dos diversos problemas que afetam a educação. Afinal, é notório que os jogos digitais são cativantes e despertam nas pessoas sentimentos de desafio, fantasia e curiosidade, elementos indispensáveis à motivação do individuo (Tapia e Fita, 1999).

O jogo EducaTrans tem como principal objetivo a educação no trânsito, um tema transversal de ensino. O público-alvo compreende alunos do Ensino Fundamental I e II e Ensino Médio. O jogador poderá escolher qual papel estará desenvolvendo no decorrer do jogo, variando entre pedestres, ciclistas e motoristas. Sabe-se que cada personagem desempenha um papel diferente no trânsito, por isso, o jogador deverá estar atento pra as leis de trânsito ao qual deverá respeitar durante o jogo. O EducaTrans utiliza algoritmos genéticos como mecanismo de evolução dos pedestres autônomos e oferece uma ferramenta divertida e desafiadora onde o aprendiz poderá navegar em um ambiente tridimensional que reproduz um cenário real com regras de trânsito bem definidas.

Este jogo foi pensado de forma a promover a meta-cognição sem minimizar os aspectos lúdicos, como proposto em (Bittencourt, 2005), de forma a não tornar o jogo somente um produto didatizado, fazendo-o perder seu caráter prazeroso e espontâneo. De acordo com Fortuna (2000), o objetivo do jogador deve ser antes de qualquer coisa, jogar, pois o que caracteriza os jogos são a espontaniedade, improdutividade, interatividade, simbolismo, desafio, mistério, surpresa, entre outras. Bittencourt, por sua vez, afirma que "O jogo por si só exercita a função representativa da cognição como um todo. O brincar desenvolve a imaginação e a criatividade".

\section{Classificação de Jogos Digitais}

A literatura pesquisada não apresentou uma classificação padronizada de jogos digitais, pois não há ainda um consenso do mundo acadêmico neste assunto. De acordo com Watt e Policarpo (2000), os tipos de jogos mais comuns são os jogos de combate, jogos corrida de carros, jogos de perseguição e jogos de estratégia.

Neste trabalho, optou-se por apresentar uma classificação mais abrangente que define sete tipos de jogos digitais, enfatizando que um jogo pode pertencer a mais de um tipo simultaneamente, porém, em níveis diferentes. Esta classificação é apresentada por Bittencout (2005) citada por (Rollings e Morris, 2000), onde o autor propõe uma classificação dos jogos destacando gêneros como uma composição de diferentes estilos classificados em: ação, aventura, estratégia, simulação, quebra-cabeça, brinquedos e educacionais. Nesta abordagem, um jogo pode apresentar níveis diferentes de cada um dos estilos. Jogos mais complexos apresentam uma mistura de estilos, são mais ricos e menos lineares. Os estilos são resumidos a seguir:

1. Ação: narrativa com movimentações e ações rápidas, onde o objetivo é deixar o jogador sempre atento. Um exemplo de jogo de ação é o jogo Counter Strike, um jogo de tiro em primeira pessoa, que pode ser jogado colaborativamente através da rede ou de forma individual (Steam Games, 2006). 
2. Aventura: narrativas heróicas que envolvem mistérios e locações que precisam ser exploradas, um exemplo é The Monkey Island (Monkey Island, 2006).

3. Estratégia: envolve raciocínio lógico, planejamento e gerenciamento de recursos, como no jogo Age of the Empires, um jogo em tempo real que coloca os jogadores no papel de potências européias determinadas a explorar, colonizar e conquistar o Novo Mundo (Ensemble Studios, 2005).

4. Simulação: manipulação e experimentação de um modelo matemático que reproduz uma situação real. Através da experimentação o jogador se aperfeiçoa de forma a dominar o modelo simulado. Flight Simulator é um exemplo de jogo de simulação de vôo, onde se pode testar e alterar as condições metereológicas e aprender sobre a história da aviação (Microsoft Game Studios, 2006).

5. Quebra-cabeça: apresenta problemas que são resolvidos com raciocínio lógicomatemático, por exemplo, o jogo Tetris, cujo objetivo é criar linhas horizontais completas com as peças que estão caindo, sem deixar buracos.

6. Brinquedo: não possui um objetivo pré-determinado nem envolve condições de vitória ou derrota. Um exemplo é o The Sims, onde o jogador escolhe dentre uma seleção de "Sims" já existentes ou cria sua própria família através da distribuição de traços de caráter para cada indivíduo (Electronic Arts, 2006).

7. Educacional: possui intenção explicita de ensinar algum conceito ou desenvolver alguma habilidade, como por exemplo, o software Editor Musical (Ficheman et al, 2003) e os aplicativos do Portal EduMusical (Ficheman et al, 2004) que permitem desenvolver habilidades musicais nos aprendizes.

\subsection{Análise dos Jogos Educacionais e Jogos de Entretenimento}

Uma reflexão sobre jogos educacionais e jogos para entretenimento permite observar semelhanças e diferenças entre os dois tipos (Tabela 1).

Tabela 1- Diferenças entre Jogos Educacionais e Jogos para Entretenimento

\begin{tabular}{|l|l|}
\hline Jogos Educacionais & Jogos para Entretenimento \\
\hline Objetivo: desenvolver habilidades ou competências & Objetivo: entreter e/ou divertir \\
\hline Atores: aprendizes e professores & Atores: jogadores \\
\hline Multiplayer - Atores colaboram & Multiplayer - Atores competem \\
\hline $\begin{array}{l}\text { Inteligência Artificial (IA): acompanha o aprendiz, } \\
\text { conhece o aprendiz (mapas conceituais), orienta o } \\
\text { aprendiz (mecanismos de aprendizagem), reporta ao } \\
\text { professor (mecanismos de avaliação). }\end{array}$ & $\begin{array}{l}\text { Inteligência Artificial (IA): } \\
\text { compete com outros jogadores. }\end{array}$ \\
\hline
\end{tabular}

Por um lado, pode-se dizer que o que faz um jogo ser educacional não é o jogo em si, mas a forma com a qual ele é utilizado e o contexto no qual ele é inserido. Em (Andrade et al, 2003) é apresentado um estudo de caso sobre o jogo "The Sims", um jogo que mistura os estilos de simulação, estratégia e brinquedo e que, apesar de não ser um jogo educacional, pode ser utilizado para desenvolver a percepção da importância da alocação de recursos na infra-estrutura de uma cidade. Alguns relatos de crianças sobre o que se pode aprender estão disponíveis em (Andrade et al, 2003). 


\section{Uma Proposta de Game Engine para Jogos Educacionais}

Uma game engine se refere ao conjunto de módulos de simulação que não especificam diretamente o comportamento do jogo (lógica do jogo) ou o ambiente do jogo (nível dados). A game engine inclui módulos de manipulação de entrada, saída (rendering 3D, desenho 2D, som), e dinâmica/física genérica para jogos (Lewis e Jacobson, 2002).

Uma game engine de um jogo pode ser considerada uma camada acima do Sistema Operacional e das bibliotecas básicas, que abstrai as complexidades das rotinas de leitura e escrita de dados, desenho, som, rede, etc. Ela facilita tarefas comuns como simulação física, além de prover uma base sólida para o desenvolvimento de jogos.

É possível verificar que existem engines que são livremente distribuídas sob a licença General Public License (GPL) como é o caso do Quake III ou Lesser General Public License (LGPL) no caso do Crystal Space. Outras engines como o Fly3D e o Genesis3D possuem uma licença proprietária, mas distribuem o código-fonte (Bittencourt et al, 2003). A game engine aqui proposta pressupõe a existência de um cenário tridimensional já criado previamente.

A game engine fica acima da plataforma de hardware, Graphics Processing Unit (GPU), do Sistema Operacional e das bibliotecas básicas. A arquitetura proposta é composta de 8 módulos. O modulo Controle recebe e fornece dados provenientes dos módulos Interação, Inteligência Artificial, Pedagógico, Física e Comunicação e alimenta os módulos Gráfico e Som para que estes criem a imagem que representa o estado atual do jogo sob a perspectiva de determinada entidade controlada pelo jogador.

\subsection{Definição dos Módulos}

A seguir são apresentados os módulos da arquitetura básica da game engine do jogo EducaTrans

Inteligência Artificial (IA): se divide em simbólica e cognitiva e dispõe de muitos recursos. Foi selecionado o seguinte subconjunto de recursos para a game engine:

- Algoritmo Genético: Conjunto de classes que implementam as principais estruturas e os operadores genéticos como cruzamento e mutação. Este pacote pode ser utilizado para gerar outros personagens de forma automática e avaliar seu desempenho através da função de fitness (Obitko, 2005).

- Tutor: Pacote de classes que implementam as principais funções dos tutores inteligentes. Os tutores têm sido largamente utilizados em ambientes de ensino-aprendizagem e têm como objetivo orientar o aprendiz durante o processo, provendo um ensino individualizado, de acordo com as necessidades do aprendiz. O tutor modela o entendimento do aprendiz sobre um tópico e à medida que ele realiza determinadas tarefas no sistema, compara o conhecimento do aprendiz com o modelo que ele tem de um especialista do domínio. Se existir uma diferença, o sistema pode usar o seu modelo de domínio para gerar uma explicação que vai auxiliar o aprendiz a compreender o que ficou mal entendido ou solicitar a cooperação ou colaboração de outros aprendizes. Além disso, o sistema pode também ajustar os níveis e estilos de aprendizagem do aprendiz e apresentar quais informações, testes e feedbacks são mais apropriados (Pozzebon et al, 2005). 
- Agente: Pacote de classes que possibilitam a implementação de sistemas multiagentes da IA distribuída. Neste trabalho, os agentes cognitivos são os mais adequados para o tipo de aplicação proposta. Um agente cognitivo se caracteriza por ser capaz de perceber seu ambiente através de sensores, reagir aos estímulos e se comunicar com outros agentes. $\mathrm{O}$ agente pode ser implementado de várias formas, por exemplo, com base na arquitetura de subfunção, que estabelece uma hierarquia de comportamentos (Steels, 1990). Para fins educacionais, o cenário pode ser dividido em regiões, onde cada região é monitorada por um agente de ensino.

Pedagógico: este módulo compreende funções didático-pedagógicas que podem ser incorporadas ao jogo. Dentre as funções analisadas, destacam-se:

- Mapa Conceitual: Este pacote implementa as classes necessárias para incorporar mapas conceituais no jogo. Mapas conceituais são recursos para a representação de conhecimento que se constituem numa rede de nós, representando os conceitos ou objetos, conectados por arcos com rótulos descritores das relações entre pares de nós (Santos et al, 2005). Eles têm sido utilizados para representar o modelo mental do estudante.

- Critérios de Aprendizagem: Este pacote implementa classes para possibilitar ao professor (ou usuário master) definir os objetivos da aprendizagem, as características dos estudantes e a apresentação e organização do conteúdo.

- Suporte à Avaliação: Este pacote inclui classes para a avaliação da aprendizagem do estudante. Devem ser disponibilizados recursos tanto para a avaliação tradicional, baseada em exames cumulativos quanto a avaliação formativa, que possibilita monitoramento e orientação contínuos do processo de aprendizagem.

Interação: neste módulo são definidos os dispositivos e mecanismos de entrada do jogo. Os usuários atuam em periféricos que geram eventos armazenados e processados pelo pacote de interação por meio de uma fila de eventos.

Gráfico: este pacote incorpora recursos diversos para o rendering da cena. Foram selecionadas algumas das classes da engine fly $3 D$ para serem incluídas neste módulo (Watt e Policarpo, 2000). Também foram definidas outras classes para a engine proposta, como por exemplo shader, que faz o cálculo da iluminação e sombreamento da cena utilizando um modelo de iluminação de Gouraud ou Phong.

Controle: Controle implementa a árvore "Binary Space Partition" (BSP) para gerenciar a cena, através da biblioteca OpenSceneGraph (Bittencourt 2005). BSP é um mecanismo de particionamento da cena e armazenamento da mesma em uma árvore. $\mathrm{O}$ módulo Controle mantém duas listas de objetos BSP, objetos ativos e inativos, como proposto na engine fly $3 \mathrm{D}$. Os objetos inativos podem ser ativados por várias condições, como por exemplo, após um certo período de tempo. Este recurso é particularmente interessante para proporcionar atividades dinâmicas e desafios ao longo do jogo.

Som: este pacote inclui recursos para o armazenamento e a geração de sons (tanto trilha sonora como efeitos sonoros).

Física: o pacote de física inclui métodos que permitem a simulação física de objetos no jogo e a colisão entre objetos geométricos. Estes métodos podem ser implementados utilizando a biblioteca OpenDE (Bittencourt 2005). 
Comunicação: este módulo proporciona a característica multiplayer do jogo. É baseado em uma arquitetura cliente-servidor.

\section{Jogo EducaTrans}

Segundo Bittencourt (2005) é fundamental elaborar uma especificação detalhada para a criação de jogos digitais. Costuma-se chamar este documento de Design Bible, que deve conter o roteiro, a conceituação artística do jogo, a jogabilidade (regras do jogo) e o projeto de interfaces.

A seguir é apresentado um resumo do documento Design Bible do jogo EducaTrans conforme o modelo recomendado por (Taylor 2005). Entretanto, elementos adicionais como objetivos pedagógicos, indicação de disciplina e interatividade foram incorporados ao documento por se tratar de um jogo educacional.

\subsection{Design Bible do Jogo EducaTrans}

1. Descrição geral do jogo: o jogo consiste em uma simulação do fluxo de pedestres, motoristas e ciclistas que partem de um mesmo ponto e buscam atingir o mesmo destino no menor tempo e com o menor risco à sobrevivência.

2. Objetivos: por ser um jogo educacional, o EducaTrans tem objetivos distintos que dependem do ponto de vista considerado. Do ponto de vista do jogador, o objetivo é chegar ao destino com o máximo de energia e o mínimo de tempo para conquistar o tesouro. Do ponto de vista educacional, o objetivo é ensinar o jogador a ser prudente no trânsito, e familiarizá-lo com as placas de trânsito.

3. Objetivos Pedagógicos: constituem as competências a serem desenvolvidas, seguindo a taxionomia de objetivos educacionais de Benjamin Bloom (cognitivos, afetivos e psicomotores) (Rodrigues, 1994). Desta forma, o jogo EducaTrans tem objetivos cognitivos nos níveis de conhecimento (leis de trânsito, sinalização de vias), compreensão (interpretação das pistas para descoberta do tesouro) e avaliação (o aprendiz é capaz de confrontar o seu desempenho com o dos demais participantes por meio das decisões tomadas e recompensas e penalidades atribuídas) e também objetivos afetivos (estimula a imaginação e autoconfiança do aprendiz).

4. Indicado para disciplina(s): este campo é importante para que o professor identifique rapidamente quais são os assuntos que podem se adequar ao jogo, ou seja, a que matérias ou conteúdos da ação didática o jogo é pertinente. EducaTrans é indicado para disciplinas de temas transversais de ensino (temas locais), de acordo com os Parâmetros Curriculares Nacionais .

5. Estratégia Pedagógica: especifica quais estratégias pedagógicas, diretiva (os conceitos são apresentados conforme a ordem especificada pelo professor), orientada por descoberta (permite ao aluno descobrir o conhecimento do sistema, direcionando seu próprio aprendizado) ou exploratória (permite que o aluno examine todo o material instrucional disponibilizado, sem qualquer comprometimento com a ordem de conceitos especificada pelo professor), são as mais adequadas para o jogo (Lima et al, 2005). No jogo EducaTrans a estratégia mais adequada é a orientada por descoberta, onde o papel do professor é de orientador durante o jogo.

6. Interatividade: aqui é definido o nível de interatividade proporcionado pelo jogo. Interatividade alta permite a descoberta imprevista e a exploração livre, 
interatividade média permite a descoberta guiada e interatividade baixa privilegia a aprendizagem de recepção direcionada. O EducaTrans apresenta um nível de interatividade média.

7. Justificativa: atualmente, muitos acidentes de trânsito são causados por imprudência de pedestres e ciclistas, por falta de conhecimento, de orientação e de familiarização com leis e placas de trânsito. A repressão com multas e penalidades não parece surtir efeito. Por outro lado, há uma carência de jogos educacionais que trabalhem a Educação no Trânsito. A disponibilização do jogo EducaTrans poderá suprir esta demanda, e contribuir com as ações, palestras, aulas, ao ser adotado nas escolas, nos telecentros e nas residências.

8. Diferencial: o jogo EducaTrans procura envolver o jogador em um ambiente imersivo, apresentando um desafio em um ambiente dinâmico e desafiador.

9. Público Alvo: os usuários potenciais do jogo EducaTrans são desde jovens recentemente alfabetizados até jovens do ensino Fundamental e ensino Médio.

10. Cenário: o jogo ocorre num centro urbano onde há trânsito de pedestres veículos e ciclistas (Figura 2). O cenário do jogo apresenta um quarteirão com vias de trânsito (ruas, avenidas, rodovias), calçadas, faixas de pedestre, rotatória, semáforos para pedestres e veículos, placas de trânsito de indicação, de advertência e de regulamentação.
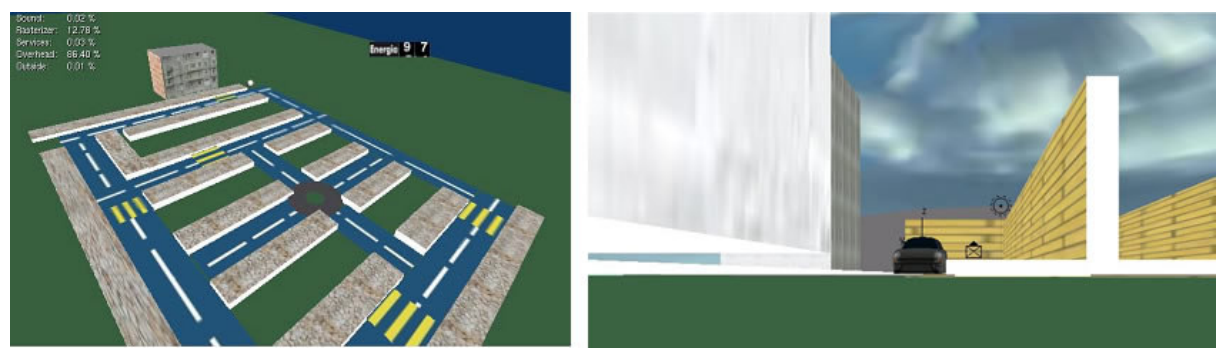

Figura 2. (a) Vista Superior do EducaTrans. (b) Veículo no cenário do jogo.

Personagens: o jogo oferece diferentes papéis, sendo estes: pedestre, motorista e ciclista. Estes papéis podem ser desempenhados por jogadores humanos interagindo com o sistema em ambientes multiplayer, ou por jogadores virtuais simulados por algoritmos de IA.

11. Início do Jogo: o jogo começa com todos os jogadores numa posição prédefinida do cenário. Cada jogador escolhe o papel que deseja desempenhar. Cada jogador possui uma barra de energia que inicialmente mostra o valor 25 , e um cronômetro que inicialmente mostra o valor 0 segundos. Os jogadores são informados que há um tesouro escondido e que o objetivo de cada jogador é encontrar o tesouro com o máximo de energia em um tempo mínimo.

12. Interação do usuário e competidores: o jogador controla apenas um personagem da "corrida". Os demais personagens são controlados no modo multiplayer por outros usuários ligados em rede, e no modo singleplayer, os demais personagens que participam da "corrida" são gerados e controlados por mecanismos de IA. Tanto o pedestre controlado pelo usuário quanto os controlados por IA possuem o mesmo tamanho de passo e estão sujeitos às mesmas limitações de tempo e colisão. E no caso de motoristas e ciclistas, eles possuem a mesma velocidade. Os usuários interagem com o sistema para fazer o 
seu personagem se deslocar no cenário usando o teclado. Setas de direção permitem avançar, recuar, virar a direita e virar a esquerda.

13. Energia e Cronômetro: a energia do jogador e o cronômetro permanecem sempre visíveis. O cronômetro mostra o tempo decorrido desde o início do jogo, e a barra de energia mostra a quantidade de energia acumulada. Inicialmente o jogador começa com energia de 25 unidades. Ao infringir uma lei de trânsito, como caminhar no meio da rua ou atravessá-la com semáforo vermelho, o usuário perde 8 unidades de energia. Entretanto, ao respeitar uma lei de trânsito, como atravessar uma rua na faixa de pedestre, ganha 10 unidades de energia.

14. Desafio e Pista: para motivar o usuário e tornar o jogo desafiador, o jogador deve descobrir a localização do tesouro, chegar antes dos outros jogadores ou dos concorrentes autônomos com mais pontos de energia. Uma pista em forma de placa de indicações aparece na tela apontando para o caminho a ser seguido.

15. Fim do jogo: o jogo termina quando o primeiro jogador encontra o tesouro ou quando o jogador perde toda energia. Por motivos educacionais, para não desestimular o aprendiz, o total de unidades de energia não pode ser negativo. Se o jogador, ao infringir uma lei de trânsito, obtiver uma energia negativa, então o jogo termina para este jogador, e o indicador de energia mostra energia igual a zero. É importante que ao final de cada etapa do jogo, o usuário possa acessar suas penalidades e recompensas bem como as dos personagens autônomos, de forma a aprender com seus erros e acertos e de seus "colegas". No final do jogo o jogador poderá observar seu histórico (caminho que fez no cenário e dos níveis de energia que acumulou a cada momento), bem como dos demais jogadores.

16. Inteligência Artificial: foi utilizado Algoritmo Genético (AG) para gerar a população de pedestres, motoristas e ciclistas autônomos. Em um AG, os problemas são solucionados por um processo evolutivo resultando em uma solução melhor, ou seja, mais adequada. O AG inicia com um conjunto de soluções (cromossomos) denominado população. As soluções de uma população são utilizadas para formar uma nova população, motivados pela esperança de que a nova população seja melhor que a primeira. As soluções selecionadas para formar novas gerações são formadas de acordo com sua adequação, quanto melhores, mais chances de reprodução (Obitko, 2005). Cada personagem (pedestre, ciclista, motorista) autônomo é representado por um código genético, onde cada gene representa um elemento da cena, ou seja, um trecho no caminho "sorteado" para o indivíduo. Cada personagem autônomo é um indivíduo da população e sua fitness é proporcional às recompensas e penalidades que ele recebeu ao longo da trajetória escolhida e inversamente proporcional à sua distância do ponto de chegada. Com os AGs, as mudanças de fases no jogo poderão ser implementadas através de novas gerações de indivíduos.

\section{Considerações Finais e Propostas para Trabalhos Futuros}

Neste trabalho foi apresentado um jogo educacional que tem por objetivo a Educação no Trânsito, um tema transversal de ensino na Educação Básica. O cenário do jogo foi desenvolvido utilizando o software de modelagem Blender 3D (Brito, 2006). O controle (placar, tempo, energia) foi implementado através de scripts na linguagem Python (Riley, 2003). A interação do jogo foi elaborada utilizando o módulo GameLogic do Blender 3D. A trilha sonora $\mathrm{e}$ os sons foram selecionados no site http://freesound.iua.upf.edu/, com a participação de uma adolescente de 14 anos, e os 
modelos 3D desenvolvidos foram acompanhados por uma criança de 9 anos, de forma a proporcionar um design participativo.

Embora a concepção pedagógica deste trabalho tenha sido implementada a contento, pretende-se, nos trabalhos futuros, realizar uma avaliação do sistema junto aos usuários, na forma de ensaio de interação, que deverão ser realizados com crianças do ensino fundamental e médio, público alvo desta aplicação e testes com especialistas em interação homem-computador para avaliar a usabilidade do jogo desenvolvido.

\section{Referências}

Andrade, L.; Zavaleta, J.; Vaz, F.; Lima, C.; Araujo, C.; Soares, A. (2003) "Jogos Inteligentes são Educacionais?". In: Simpósio Brasileiro de Informática na Educação. Anais. Rio de Janeiro, RJ.

Bittencourt, J. R.; "Promovendo a Ludicidade Através de Jogos Livres". (2005) In: Simpósio Brasileiro de Informática na Educação. Minicursos. Juiz de Fora, MG.

Bittencourt, J. R.; Giraffa, L. M.; Santos, R. C. (2003) "Criando Jogos Computadorizados Multiplataforma com Amphibian”. In: Simpósio Brasileiro de Informática na Educação. Anais. Rio de Janeiro, RJ.

Brito, A. (2006) "Blender 3D - Guia do Usuário. Ed. Novatec". 1ª edição, 448p.

Eletronic Arts (2006). “The Sims”. Disponível em < http://thesims.ea.com/>. Acesso em Agosto 2006.

Ensemble Studios. (2005) "Age of Empires III" Disponível em < http://www.ageofempires3.com/ >. Acesso em Agosto 2006.

Ficheman, I. K.; Lipas, R. A.; Krüger, S. E.; Lopes, R. D.; (2003) "Editor Musical: uma Aplicação para a Aprendizagem de Música apoiada por Meios Eletrônicos Interativos". In: Simpósio Brasileiro de Informática na Educação. Anais. Rio de Janeiro, RJ.

Ficheman, I. K.; Lopes, R. D.; Krüger, S. E.; Netto, O. B.; (2004) "PORTAL EDUMUSICAL: Telemática aplicada à Educação Musical”. In: Simpósio Brasileiro de Informática na Educação. Anais. Manaus-AM.

Fortuna, T. R. (2000) "Sala de aula é lugar de brincar?". In: Planejamento, Análises menos convencionais, Organizador por Xavier M. L. F.; Dalla Zen, M. I. H., Mediação, Porto Alegre-RS.

Lewis, M.; Jacobson, J. (2002) "Game Engines in Scientific Research". In: Communications of the ACM. Jan 2002, v. 45, n.1, 27-31.

Lima, G. C. B.; Zanella, R.; Menezes, P. B. (2005) "AdaptHA: Ambiente de Ensino Adaptativo na Web Baseado no Modelo Hyper-Automaton” In: Simpósio Brasileiro de Informática na Educação. Anais. Juiz de Fora, MG.

Microsoft Game Studios. (2006) "Microsoft Flight Simulator Inside”. Disponível em <http://www.fsinsider.com/> Acesso em Agosto 2006.

Monkey Island. (2006) "The World of Monkey Island". Disponível em < http://www.worldofmi.com/>. Acesso em Agosto 2006.

Obitko, M. (1998) "Introduction to genetic algorithms with Java applets". Disponível em: <http://cs.felk.cvut.cz/ xobitko/ga/>. Acessado em:23 abr. 2005. 
Pozzebon, E.; Bittencourt, G.; Cardoso, J. (2005). "Uma Arquitetura Multiagente para Suporte ao Aprendizado em Grupo em Sistemas Tutores Inteligentes". In: Simpósio Brasileiro de Informática na Educação. Anais. Juiz de Fora, MG.

Riley, S. (2003) “Game Programming With Python”. Ed. Charles R. M. $1^{\text {a }}$ ed., 488p.

Rodrigues, J. (1994) "A taxonomia de objetivos educacionais - um manual para o usuário.” Editora UNB, 2 edição.

Santos, P. S.; Menezes, C. S.; Cury, D.; Nevado, R. A. (2005) "Um Ambiente para Acompanhamento da Aprendizagem baseado em Mapas Conceituais" In: Simpósio Brasileiro de Informática na Educação. Anais. Juiz de Fora, MG.

Steam Games (2006). "Counter-Strike Official Site”. Disponível em http://www.counter-strike.net/. Acesso em Agosto 2006.

Steels, L. (1990) "Cooperation between Distributed Agents through Self-Organization". In Decentralized A.I. Demazeau, Y. e Muller, J-P. (Eds), North-Holand, Amsterdam.

Tapia, J. A., Fita; E. C., (1999) “A motivação em sala de aula - o que é, como se faz”. Ed. Loyola Ltda. São Paulo - SP.

Taylor, C. (2005) “Design Document Template”. Disponível em: http://www.ihfsoft.com/ctaylordesigntemplate.zip. Acesso em Novembro 2005.

Valente, J. A. (1999) "O Computador na Sociedade do Conhecimento". NIED, Campinas, p 71-85.

Watt, A.; Policarpo, F. “3d Games: Real-Time Rendering and Software Technology". Addison-Wesley, 2000, v. 1, 800 p. 